\title{
L-Arginine/Korean Ginseng/Ginkgo biloba/Damiana-Based Supplement
}

National Cancer Institute

\section{Source}

National Cancer Institute. L-Arginine/Korean Ginseng/Ginkgo biloba/Damiana-Based

Supplement. NCI Thesaurus. Code C67093.

An amino acid and herbal supplement with libido-enhancing activity. L-arginine/Korean ginseng/Ginkgo biloba/Damiana-based supplement contains a blend of the amino acid Larginine and the herbs Korean ginseng, Ginkgo biloba, and damiana (T urnera aphrodisiaca) in addition to 14 other vitamins and minerals. The semi-essential amino acid L-arg inine is a precursor for nitric oxide (NO); Korean ginseng may enhance the conversion of L-arginine into NO by NO synthase; and Ginkgo biloba may promote microvascular circulation. This agent may increase NO production, resulting in vasodilatation and an enhanced circulation critical to sexual function and arousal. The damiana component may exert an anxiolytic effect and stimulate sexual behavior. 